\title{
Infants' Haptic Discrimination of Spatial Orientations
}

\author{
E. Gentaz and A. Streri
}

\section{(2) OpenEdition}

1 Journals

\section{Electronic version}

URL: http://journals.openedition.org/cpl/387

DOI: $10.4000 / \mathrm{cpl} .387$

ISSN: $1379-6100$

\section{Publisher}

Centre PsyCLÉ

Printed version

Date of publication: 1 December 2002

\section{Electronic reference}

E. Gentaz and A. Streri, «Infants' Haptic Discrimination of Spatial Orientations », Current psychology letters [Online], 2002/3, 9 | 2002, Online since 22 September 2003, connection on 08 September 2020 URL : http://journals.openedition.org/cpl/387 ; DOI : https://doi.org/10.4000/cpl.387

This text was automatically generated on 8 September 2020

(C) All rights reserved 


\title{
Infants' Haptic Discrimination of Spatial Orientations
}

\author{
E. Gentaz and A. Streri
}

